\title{
Effect of Dietary Inclusion of Gynura divaricata (L.) on Growth Performance, Hematology, and Carcass Fat Deposition in Broilers
}

\author{
Chairat Jamjang $^{1}$, Suwanna Kijpakorn ${ }^{1}$ and Kris Angkanaporn ${ }^{2}$ \\ ${ }^{1}$ Department of Animal Husbandry, Faculty of Veterinary Science, Chulalongkorn University, Bangkok, Thailand \\ ${ }^{2}$ Department of Veterinary Physiology, Faculty of Veterinary Science, Chulalongkorn University, Bangkok, Thailand
}

\begin{abstract}
The objective of this study was to examine the effect of Gynura divaricata (Jakr-Na-Rai, JNR) on the growth performance, hematology, and carcass fat deposition of broilers. A total of 240 male Cobb-500 birds, $22 \mathrm{~d}$ old, were randomly allocated into five treatment groups of six replicates. Each group was raised at a high stocking density of 28 $\mathrm{kg}$ of body weight $/ \mathrm{m}^{2}$ until day 43 . The treatments consisted of (i) a basal diet, or the basal diet supplemented with (ii) $2.5 \mathrm{mg} / \mathrm{kg}$ avilamycin (T2), (iii) JNR crude ethanol extract at a flavonoid level of $1.3 \mathrm{~g} / \mathrm{kg}$ (T3), and (iv and v) JNR powder at a flavonoid level of 1.3 (T4) or $2.6 \mathrm{~g} / \mathrm{kg}$ (T5). Dietary supplementation with JNR powder at both flavonoid levels decreased the heterophil/lymphocyte ratio compared to the other groups $(P<0.001)$. Birds in the T5 group presented decreased blood glucose $(P<0.005)$ and cholesterol $(P<0.002)$ levels and a numerically $(P=0.056)$ decreased triglyceride level. The total bile acid concentration increased $(P<0.001)$ in all the JNR-fed groups, but there was no significant effect on the digestibility of ileal protein or fat. At $1.3 \mathrm{~g} / \mathrm{kg}$ of diet, JNR increased the final body weight and feed intake $(P<0.05)$, but the average daily gain and feed conversion ratio were not different among groups. The carcass and abdominal fat percentages were lowest in chicks fed on the diets supplemented with $2.6 \mathrm{~g} / \mathrm{kg}$ JNR powder $(P<0.007$ and $P<0.025$, respectively). Drip loss and malondialdehyde concentrations in the breast meat did not change. In conclusion, JNR powder improved several hematological parameters, increased total bile acid concentrations, and decreased the percentage of abdominal fat. The powder form of JNR elicited better results than the ethanol extract form at the same flavonoid inclusion level.
\end{abstract}

Key words: abdominal fat, cholesterol, flavonoid, glucose, heterophil/lymphocyte ratio, polysaccharide

J. Poult. Sci., 57: 114-123, 2020

\section{Introduction}

Herbal products are increasingly used as alternatives to antibiotic growth promoters (AGP) in the broiler industry owing to their abundant active ingredients and varied properties (Cheng et al., 2014). Jakr-Na-Rai [JNR, Gynura divaricata (L.)], a traditional Chinese medicinal herb (Bai Bei San Qi), is rich in active ingredients and can be easily grown in Thailand and Southeast Asia (Jaiboon et al., 2011). To date, the active ingredients reported for JNR include flavonoids (Wan et al., 2011b; Wu et al., 2011), cerebrosides (Chen et al., 2009), alkaloids (Roeder et al., 1996), polysac-

Received: October 11, 2018, Accepted: June 21, 2019

Released Online Advance Publication: September 25, 2019

Correspondence: Dr. Kris Angkanaporn, Department of Veterinary Physiology, Faculty of Veterinary Science, Chulalongkorn University, Phyathai Rd., Pathumwan, Bangkok 10330, Thailand. (E-mail: Kris.A@chula.ac.th) The Journal of Poultry Science is an Open Access journal distributed under the Creative Commons Attribution-NonCommercial-ShareAlike 4.0 International License. To view the details of this license, please visit (https:// creativecommons.org/licenses/by-nc-sa/4.0/). charides, terpenoids, and $\beta$-sitosterol (Chen et al., 2003). The major active substances in JNR are the flavonoids, with kaempferol comprising the main portion (Wan et al., 2011a), and polysaccharides (Deng et al., 2011). Flavonoids can increase bile acid secretion (Crespy et al., 2003), thereby assisting in fat digestion (Lammasak, 2010). Polysaccharides can also lower blood glucose levels (Jiang et al., 2009; Deng et al., 2011). With limited glycogen deposition in the liver, birds survive reductions in blood sugar levels through gluconeogenesis from triglyceride breakdown in adipose tissues (North, 1984; Griffin et al., 1992). Aritajat et al. (2008) found that the crude water extract of JNR reduced blood triglyceride levels in chickens, suggesting that JNR may help to enhance fat degradation, resulting in reduced body fat deposition in the carcass. Relatively few studies have reported on the effect of JNR on blood cholesterol levels, and the results are still controversial. In male rats, cholesterol levels increased when they were fed with a water extract from fresh JNR leaves (Aritajat et al., 2008); in rabbits, meanwhile, no effect was found when the animals were fed with JNR from fresh whole plants (Keeratikajorn et 
al., 2012). However, there are still no reports on JNR in broilers.

Previous studies on JNR have produced inconsistent results, which may have been due to the different plant parts, extraction methods, and species of test animal used in the experiments. The ethanol extract of JNR yields several flavonoids and phenolic compounds that may be useful as antioxidants and in promoting broiler growth (Xu and Zhang, 2017). However, the composition and active ingredients of the ethanol extract of JNR may be different from that of the powder form of the whole plant. Moreover, the effects elicited by the ethanol extract form and the crude powder form of JNR, which is more practical for use by the farmer, may also differ.

Therefore, the aim of this study was to examine the effect of dietary supplementation with various forms of JNR on the growth performance, total bile acid concentration (TBAC), nutrient digestibility, and blood parameters of broiler chickens. Moreover, changes in lipid peroxidation in the plasma and breast meat, carcass fat deposition, and drip loss in breast meat of the broilers were also investigated.

\section{Materials and Methods}

\section{Animals and Management}

A total of 300 male Cobb-500 chicks were raised under a normal stocking density $\left(10\right.$ chicks $/ \mathrm{m}^{2}$ or $\left.20 \mathrm{~kg} / \mathrm{m}^{2}\right)$ at the starting period in an open-sided housing system, according to the recommendation of the Department of Livestock Development, Thailand (DLD, 2003). At $22 \mathrm{~d}$ of age, 240 birds were randomly allocated into five groups (six replicates of eight birds) and raised in floor pens in an open-sided housing system under a high stocking density (14 birds $/ \mathrm{m}^{2}$ or $28 \mathrm{~kg}$ of body weight $(\mathrm{BW}) / \mathrm{m}^{2}$ ) until $43 \mathrm{~d}$ of age. All chicks received the Newcastle-infectious bronchitis vaccine at the hatchery and the infectious bursal disease vaccine at $14 \mathrm{~d}$ of age. The birds had free access to their respective diets and water throughout the experimental period (22-43 d of age). This experiment was approved by the Animal Care and Use Committee of the Faculty of Veterinary Science, Chulalongkorn University (Approval No. 1431002).

\section{Preparation of JNR Powder and Crude Ethanol Extract Granules}

The JNR was cultivated at the veterinary training center in Nakorn Pathom province, Thailand. Plants of JNR at the height approximately of $30 \mathrm{~cm}$ were cut from the upper tip of the whole plant, washed with tap water, and used to prepare both the powder and derived crude ethanol extract (CEE) forms. The JNR was first prepared by separating the fresh leaves from the stem, chopping the stem into $1-\mathrm{cm}$ long pieces, and air drying both for $1 \mathrm{~d}$.

For the CEE, the air-dried JNR was extracted with $95 \%$ $(\mathrm{v} / \mathrm{v})$ ethanol in an Erlenmeyer flask at a $10 \%(\mathrm{w} / \mathrm{v})$ ratio for $7 \mathrm{~d}$ with stirring four times/d. Then, the ethanol solution was filtrated and evaporated in a rotary vacuum evaporator (EYELA rotary vacuum evaporator ${ }^{\circledR}$, EYELA, Tokyo, Japan) to yield the CEE (Intajak et al., 2012). To ensure a thorough distribution in the broiler diet, the CEE was then produced
Table 1. Chemical composition of the CEE granule and powder forms of JNR (g/kg DM)

\begin{tabular}{lcc}
\hline \multicolumn{1}{c}{ Nutritional content } & CEE $^{1}$ & Powder \\
\hline Protein & 87.0 & 184 \\
Crude fat & 43.0 & 34.1 \\
Crude fiber & 17.2 & 144 \\
Ash & 32.2 & 162 \\
Calcium & 1.15 & 15.1 \\
Phosphorus & 2.00 & 5.80 \\
Total flavonoid & 117 & 31.6 \\
(mg flavonoid/g DM) & 14.8 & 10.9 \\
Calculated ME, MJ/kg & \\
\hline
\end{tabular}

${ }^{1}$ Extract from diluted to granule form.

${ }^{2}$ Metabolizable energy (ME) values were calculated using an equation from AAFCO (2000).

$\mathrm{CEE}=$ crude ethanol extract; JNR $=$ Jakr-Na-Rai; $\mathrm{DM}=$ dry matter; $\mathrm{ME}=$ metabolizable energy.

in granule form. For this, the CEE was diluted with propylene glycol at a 1:1 (w/w) ratio and then mixed with ground corn $(0.85 \mathrm{~mm}$ particle size) at a ratio of $1: 9(\mathrm{w} / \mathrm{w})$ in a vertical mixer for $30 \mathrm{~min}$. The moist granules were then dried in an oven (Menmert ${ }^{\circledR}$ Ule 800, Manmert, Schwabach Germany) at $50^{\circ} \mathrm{C}$ for $2 \mathrm{~h}$.

The JNR powder was prepared by drying the previously air-dried leaves and chopped stems in an oven at $50^{\circ} \mathrm{C}$ for 48 h. When cooled, both parts were mixed and ground through a 1-mm diameter sieve blender (Retsch ${ }^{\circledR}$, Haan, Germany).

Both the powder and CEE forms of JNR were lightprotected in black plastic bags and stored at $-20^{\circ} \mathrm{C}$ until use. In addition, they were randomly sampled and analyzed for moisture, crude protein, ether extract, crude fiber, ash, calcium, and phosphorus contents using AOAC procedures 934.01, 976.05, 920.39, 962.09, 942.05, 927.02, and 964.06, respectively (AOAC, 1990). The metabolizable energy (ME) content of both JNR forms was calculated using an equation from AAFCO (2000), while the total flavonoid content was evaluated as previously described (Wan et al., 2011a). The analytical values of the nutritional composition of the powder and CEE forms of JNR are depicted in Table 1. Feed Formulation and Broiler Feeding

All the diets were formulated to be isocaloric and isonitrogenous according to the recommendations for the breed (Cobb, 2010). To ensure an even distribution of dietary nutrients, $84 \%$ of the basal grower-finisher diet was blended in one batch and used for all the treatment groups. The remaining $16 \%$ was formulated by adding JNR (powder or CEE granules) and balancing the nutrients with corn, soybean meal, and Leucaena meal. The quantity of JNR added to the diets was determined by the level of flavonoids added to the diet, and set at 1.3 or $2.6 \mathrm{~g} / \mathrm{kg}$ of diet. This level was based on a previous finding that $100 \mathrm{mg}$ of flavonoids $/ \mathrm{kg}$ of BW elicited a beneficial effect on lipid peroxidation in an induced rat model of colorectal cancer (Nirmala and Ramanathan, 2011). Thus, $100 \mathrm{mg}$ of flavonoids $/ \mathrm{kg}$ of BW, as well as the BW and feed intake of broilers at $42 \mathrm{~d}$, based 
Table 2. Composition of the experimental diets (g/kg of diet)

\begin{tabular}{|c|c|c|c|c|c|}
\hline & \multicolumn{5}{|c|}{ Treatment $^{1}$} \\
\hline & $\mathrm{T} 1$ & $\mathrm{~T} 2$ & $\mathrm{~T} 3$ & T4 & T5 \\
\hline Corn & 579 & 579 & 459 & 560 & 539 \\
\hline Soybean meal $48.5 \% \mathrm{CP}^{6}$ & 227 & 227 & 227 & 218 & 208 \\
\hline Leucaena meal & 50 & 50 & 50 & 32 & 10 \\
\hline Full fat soy & 50 & 50 & 50 & 50 & 50 \\
\hline Rice bran oil & 50 & 50 & 50 & 50 & 50 \\
\hline Mono-DicalPO 4 & 12 & 12 & 12 & 12 & 12 \\
\hline $\mathrm{CaCO}_{3}$ & 18 & 18 & 18 & 18 & 18 \\
\hline $\mathrm{NaCl}$ & 4.8 & 4.8 & 4.8 & 4.8 & 4.8 \\
\hline DL-methionine & 2.6 & 2.6 & 2.6 & 2.6 & 2.6 \\
\hline L-lysine & 1.5 & 1.5 & 1.5 & 1.5 & 1.5 \\
\hline L-Threonine & 0.5 & 0.5 & 0.5 & 0.5 & 0.5 \\
\hline Choline chloride $60 \%$ & 3.3 & 3.3 & 3.3 & 3.3 & 3.3 \\
\hline Vitamin premix ${ }^{2}$ & 0.5 & 0.5 & 0.5 & 0.5 & 0.5 \\
\hline Mineral premix ${ }^{3}$ & 0.1 & 0.1 & 0.1 & 0.1 & 0.1 \\
\hline Salinomycin $12 \%$ & 0.5 & 0.5 & 0.5 & 0.5 & 0.5 \\
\hline Surmax, avila $10 \%$ & - & 0.025 & - & - & - \\
\hline CEE JNR ${ }^{4,5}$ & - & - & 12 & - & - \\
\hline JNR powder & - & - & - & 46.1 & 99.2 \\
\hline
\end{tabular}

${ }^{1}$ Treatments: T1 control, T2 avilamycin, T3 CEE JNR granules ( $0.13 \%$ flavonoid), T4 JNR powder $(0.13 \%$ flavonoid), and T5 JNR powder $(0.26 \%$ flavonoid).

${ }^{2}$ Vitamin premix/kg of diet contained: A, 12,000 IU; D3, 3,000 IU; E, $15 \mathrm{mg}$; K3, $1.5 \mathrm{mg}$; B1, $1.8 \mathrm{mg}$; B2, $5.5 \mathrm{mg}$; B6, $2 \mathrm{mg}$; B12, $0.01 \mathrm{mg}$; Niacin, $25 \mathrm{mg}$; Calcium D-pantothenate, $12 \mathrm{mg}$; folic acid, $0.5 \mathrm{mg}$; and Biotin, $0.12 \mathrm{mg}$.

${ }^{3}$ Mineral premix/kg of diet contained: Mn, $80 \mathrm{mg}$; Zn, $60 \mathrm{mg}$; Fe, $40 \mathrm{mg}$; Cu, $8 \mathrm{mg}$; I, $0.5 \mathrm{mg}$;

$\mathrm{Co}, 0.1 \mathrm{mg}$; and $\mathrm{Se}, 0.1 \mathrm{mg}$.

${ }^{4} \mathrm{CEE}=$ crude ethanol extract; ${ }^{5} \mathrm{JNR}=\mathrm{Jakr}-\mathrm{Na}-\mathrm{Rai} ;{ }^{6} \mathrm{CP}=$ crude protein.

Table 3. Chemical analysis of the experimental diets $(\mathrm{g} / \mathrm{kg}$ diet, unless otherwise specified)

\begin{tabular}{lrrrrr}
\hline \hline \multirow{2}{*}{$\begin{array}{c}\text { Nutritional } \\
\text { content }\end{array}$} & \multicolumn{5}{c}{ Treatments $^{1}$} \\
\cline { 2 - 6 } & \multicolumn{1}{c}{ T1 } & \multicolumn{1}{c}{ T2 } & \multicolumn{1}{c}{ T3 } & \multicolumn{1}{c}{ T4 } & \multicolumn{1}{c}{ T5 } \\
\hline Crude protein & 200 & 200 & 198 & 198 & 199 \\
Ether extract & 95.1 & 94.3 & 94.3 & 95.3 & 95.5 \\
Crude fiber & 45.3 & 44.1 & 45.5 & 45.2 & 44.1 \\
Ash & 56.4 & 57.2 & 57.0 & 59.6 & 57.1 \\
Calcium & 8.8 & 8.9 & 8.7 & 8.8 & 8.7 \\
Total-P & 5.8 & 5.8 & 5.7 & 5.7 & 5.7 \\
ME (MJ/kg) & 15.2 & 15.1 & 15.1 & 15.1 & 15.2 \\
\hline
\end{tabular}

${ }^{1}$ Treatments: T1 control, T2 avilamycin, T3 crude ethanol extract (CEE) of Jakr-NaRai (JNR) granules ( $0.13 \%$ flavonoid), T4 JNR powder $(0.13 \%$ flavonoid), and T5 JNR powder $(0.26 \%$ flavonoid $)$.

${ }^{2}$ Metabolizable energy (ME) values were calculated using an equation from AAFCO (2000).

on the recommendation for the breed, were used to calculate the flavonoid doses for inclusion in the diets. Five dietary treatments were evaluated using the standard basal diet for the breed supplemented with (i) nothing (control), (ii) avilamycin at $2.5 \mathrm{mg} / \mathrm{kg}$ Surmax $^{\mathrm{TM}}$, avila $10 \%$, Eli Lilly, USA), (iii) JNR as CEE granules at a flavonoid level of 1.3 $\mathrm{g} / \mathrm{kg}$ of diet, and (iv and v) JNR powder at a flavonoid level of 1.3 or $2.6 \mathrm{~g} / \mathrm{kg}$, respectively. The composition (ingre- dients) of each diet is shown in Table 2. After formulation, samples from each diet were analyzed for nutrient and $\mathrm{ME}$ composition as described above. The chemical composition of each experimental diet is shown in Table 3.

\section{Data and Sample Collection}

The daily temperature and relative humidity $(\mathrm{RH})$ were recorded at 08:00, 12:00, and 16:00. The average temperature and $\mathrm{RH}$ in the experimental period were $31.8 \pm 1.9^{\circ} \mathrm{C}$ 
and $81.4 \pm 7.2 \%$, respectively. The weight and feed intake of the broilers were recorded at 22 and $41 \mathrm{~d}$ of age and the values used to evaluate growth performance. Mortality was recorded daily.

On days $39-41,20 \mathrm{~g} / \mathrm{kg}$ of acid insoluble ash (AIA) was mixed into the diets as an indigestible marker for analysis of the ileal digestibility of fat and protein. On day 42, two birds were randomly selected from each pen and euthanized by intracardiac injection with sodium pentobarbital $(100 \mathrm{mg} / \mathrm{kg}$ of BW). The abdomens of the chicks were then opened and the jejunal (from the duodenum to Meckel's diverticulum) and ileal (from Meckel's diverticulum to the ileocecal junction) contents were individually collected by gently squeezing the contents into a plastic bottle. Samples of jejunal or ileal contents from two birds in each pen were equally pooled, forming one sample to represent one replication, and stored at $-20^{\circ} \mathrm{C}$ until analysis. The jejunal contents were analyzed for TBAC as previously reported (Chong, 2006). The ileal content samples, as well as the diets, were analyzed for protein and the ether extract composition using AOAC procedures 976.05 and 920.39, respectively (AOAC, 1990). The AIA was analyzed using the methods of Angkanaporn et al. (1996). The analyzed values were used to calculate the nutrient digestibility coefficient.

On day 43, two birds were randomly sampled from each pen and fasted for $3 \mathrm{~h}$. The birds were individually weighed and blood was collected from the wing vein using a $22 \mathrm{G}, 1-$ inch needle. Blood droplets from each bird were immediately used to determine blood glucose levels using a digital blood glucose kit (Accu-Check Advantage II ${ }^{\circledR}$, Roche, Switzerland) (Meex et al., 2006) and the remainder were harvested into three blood collection tubes. The first tube contained EDTA for blood constituent analysis of white blood cell (WBC), packed cell volume (PCV), heterophil $(\mathrm{H})$, and lymphocyte (L) levels. The second tube contained heparin for blood chemistry analysis (cholesterol and triglyceride levels). Both tubes were sent to the Small Animal Hospital, Faculty of Veterinary Science, Chulalongkorn University, for the respective blood constituent and blood chemistry analyses using the CELL-DYN 3700 system (Interbio-Lab Inc., Orlando, FL, USA). The third tube also contained heparin, but the plasma was centrifuged at $300 \times g$ for $5 \mathrm{~min}$ (NF 800R, Nüve Sayani Malzemeler, Istanbul, Turkey) and then stored at $-80^{\circ} \mathrm{C}$ for subsequent analysis of the concentrations of thiobarbituric acid-reactive substance (TBARS). Blood samples were collected from two additional birds from each replicate after fasting overnight for $8 \mathrm{~h}$; the birds were subsequently euthanized by cervical dislocation, bled, dipped in hot water for $1 \mathrm{~min}$, the feathers removed, and the carcass immersed in an icebox for $30 \mathrm{~min}$. The carcass was then opened and both the giblets and abdominal fat pad were removed. The carcass and the abdominal fat pad were weighed and the values used to calculate the percentage of carcass and abdominal fat pad based on the relative live weight, as previously described (Dong et al., 2007). The breast meat was separated into left and right parts; the left part was used to measure drip loss
(Honikel, 1998), while the right part was stored in a plastic bag at $-80^{\circ} \mathrm{C}$ for subsequent TBARS analysis.

\section{Sample Analysis}

The total flavonoid content was analyzed as described by Wan et al. (2011a). In brief, approximately $0.3 \mathrm{~mL}$ of the CEE of JNR was pipetted into a test tube and $8 \mathrm{~mL}$ of $10 \%$ $(\mathrm{w} / \mathrm{v})$ aluminum chloride and $4 \mathrm{~mL}$ of $0.2 \mathrm{M}$ sodium acetate were added. The mixture was vortexed and immediately diluted with $12.7 \mathrm{~mL}$ of deionized distilled water with thorough mixing and then left at room temperature for 30 min. The absorbance of the reaction mixture was monitored at $350 \mathrm{~nm}\left(\mathrm{~A}_{350}\right)$ with a UV-VIS double-beam spectrophotometer (UV-VIS 160A, Shimadzu, Tokyo, Japan) and compared with a kaempferol standard curve.

Plasma TBARS was determined as previously described (Feix et al., 1991), with some modifications. Samples (600 $\mu \mathrm{L}$ each) were mixed with $120 \mu \mathrm{L}$ of $50 \mathrm{nmol} / \mathrm{L}$ butylated hydroxytoluene (BHT) and $1.8 \mathrm{~mL}$ of $10 \%(\mathrm{w} / \mathrm{v})$ trichloroacetic acid and incubated for $10 \mathrm{~min}$ at $4^{\circ} \mathrm{C}$ before being centrifuged at $300 \times g$ for $10 \mathrm{~min}$. Then, $1.5 \mathrm{~mL}$ of the harvested supernatant was mixed with $1.5 \mathrm{~mL}$ of $5 \%(\mathrm{w} / \mathrm{v}) \mathrm{TBA}$ and heated for $15 \mathrm{~min}$ in boiling water. The absorbance was read at $532 \mathrm{~nm}\left(\mathrm{~A}_{532}\right)$ using a UV-VIS spectrophotometer and compared to a standard curve derived from $0,2,4,6,8$, and $10 \mathrm{nM} \mathrm{1,1,3,3-tetraethoxypropane.} \mathrm{The} \mathrm{TBARS} \mathrm{values}$ were expressed as nmol of malondialdehyde (MDA)/mL.

The TBAC was determined as described by Chong (2006). The jejunal content was freeze-dried at $-60^{\circ} \mathrm{C}$ using a lyophilizer (Labconco ${ }^{\circledR}$, Kansas city, MO, USA), ground with a pestle and mortar, and weighed, following which distilled water was added at $0.3 \mathrm{~mL} / \mathrm{mg}$. The mixed solution was then clarified by centrifugation $\left(2,000 \times g\right.$ at $4{ }^{\circ} \mathrm{C}$ for $\left.5 \mathrm{~min}\right)$ and the harvested supernatant was used to determine the TBAC using a test kit (DZ042A, Diazyme Laboratories, Poway, CA, USA). For this, $270 \mu \mathrm{L}$ of $0.1 \mathrm{mmol}$ Thio-NAD was pipetted into a cuvette, $4 \mu \mathrm{L}$ of supernatant or distilled water (as blank) was added, followed by incubation at $37^{\circ} \mathrm{C}$ for 3 min. Then, $90 \mu \mathrm{L}$ of $0.1 \mathrm{mmol}$ of a mixture of $3 \alpha-\mathrm{HSD}$ and $\mathrm{NADH}$ was added and the absorbance was immediately monitoring at $405 \mathrm{~nm}\left(\mathrm{~A}_{405}\right)$ for $2 \mathrm{~min}$. The $\Delta \mathrm{A}_{405}(\mathrm{~nm} / \mathrm{min})$ for the sample, standard, or blank was obtained by subtracting the $\mathrm{A}_{405}$ at $60 \mathrm{~s}$ from that at $120 \mathrm{~s}$.

The TBAC was calculated using Equation (1).

$$
\begin{aligned}
& \text { TBAC }(\mathrm{mmol} / \mathrm{L})= \\
& \left(\frac{\Delta \mathrm{A}_{405} \text { sample }-\Delta \mathrm{A}_{405} \text { blank }}{\Delta \mathrm{A}_{405} \text { standard }-\Delta \mathrm{A}_{405} \text { blank }}\right) \times \text { standard. }
\end{aligned}
$$

The TBARS value of the breast meat was determined as previously described (Cherian et al., 1996). In brief, breast meat was thawed, $2 \mathrm{~g}$ of tissue was placed in a $50-\mathrm{mL}$ test tube, and $18 \mathrm{~mL}$ of $3.86 \%(\mathrm{v} / \mathrm{v})$ perchloric acid was added; the tissue was homogenized with a Polytron (Poly PTMR3100, Kinnematica AG, Littau, Switzerland) for $30 \mathrm{~s}$ at $5,000 \mathrm{rpm}$, with $1 \mathrm{~mL}$ of BHT solution being added during homogenization to control the lipid oxidation reaction. The homogenate was then filtered through Whatman filter paper No. 1 , and $2 \mathrm{~mL}$ of the filtrate was mixed with $2 \mathrm{~mL}$ of a 20 
$\mathrm{mM}$ TBA reagent, incubated in a boiling water bath for 30 $\mathrm{min}$, and then left to cool for $45 \mathrm{~min}$. The absorbance of the filtrate at $532 \mathrm{~nm}\left(\mathrm{~A}_{532}\right)$ was monitored using a double-beam UV-VIS spectrophotometer (UV-160 A, Shimadzu) and compared with a malondialdehyde tetrabutylammonium salt solution standard curve. The TBARS values were expressed as $\mathrm{mg}$ of MDA $/ \mathrm{kg}$ of tissue.

\section{Statistical Analysis}

For dependent variables (blood constituents and blood chemistry parameters, TBAC, ileal nutrient digestibility coefficient, carcass and abdominal fat percentage, and drip loss and MDA in plasma and breast meat), two birds per pen from the grower-finisher period were used. Growth performance variables were analyzed per pen. Statistical analysis for all the dependent variables was performed as a completely randomized design using one-way analysis of variance (ANOVA) to determine treatment effects (SAS, 2002). Differences among means were compared by the Bonferroni method; $P$-values $<0.05$ were considered significant.

\section{Results}

The nutrient composition and flavonoid levels of the JNR powder and CEE granule forms are shown in Table 1. The JNR powder had higher protein (2.1-fold), fiber (8.4-fold), calcium (13.1-fold), and phosphorus (2.9-fold) contents than the CEE granule form, but lower fat (1.3-fold), total flavonoid (3.7-fold), and ME (1.4-fold) contents. However, as stated above, the inclusion level of JNR in the diets (Table 2) was calculated based on total flavonoid levels. The analytical value of all the nutrients and the calculated ME of all the diets were near identical (Table 3).

\section{Blood Constituents, Blood Chemistry, and Plasma Lipid Peroxidation}

For the broiler blood constituent parameters, the PCV and WBC count did not differ among the five treatment groups, but the levels of $\mathrm{H}$ and $\mathrm{L}$ were significantly decreased $(P=$ $0.005)$ and increased $(P=0.028)$, respectively; this led to a significantly smaller $\mathrm{H} / \mathrm{L}$ ratio in birds fed the diet with JNR powder at $1.3 \mathrm{~g} / \mathrm{kg}$ compared to the control and antibiotic groups (Table 4). However, increasing the JNR powder level from a 1.3 to $2.6 \mathrm{~g} / \mathrm{kg}$ flavonoid dosage did not result in significantly different broiler blood parameters.

Blood chemistry analysis showed that glucose and cholesterol levels were significantly decreased $(P=0.005$ and 0.002 , respectively) in the diets containing powder JNR at a $2.6 \mathrm{~g} / \mathrm{kg}$ flavonoid dose. Triglyceride concentrations in the broilers from all three JNR-fed groups were considerably lower than those in the control and antibiotic fed groups $(P=$ $0.056)$, while there was no significant difference in plasma lipid peroxidation levels (as MDA) among all the treatment groups $(P>0.05)$.

\section{TBAC and Ileal Nutrient Digestibility Coefficient}

The TBAC (Table 5) increased significantly in birds fed with diets containing the powder or CEE forms of JNR $(P=$ $0.001)$ compared to the control or antibiotic groups. However, the crude protein and ether extract digestibility coefficients were not different among all the groups.

\section{Growth Performance}

The average BW of the birds at the start of the trial (at $22 \mathrm{~d}$ of age) was not significantly different among the five groups, but by $41 \mathrm{~d}$ of age, the average BW of birds fed with either the CEE or powder forms of JNR at a flavonoid level of 1.3 $\mathrm{g} / \mathrm{kg}$ of diet was significantly higher than that in the control

Table 4. Effect of treatments on blood constituents, blood chemistry, and thiobarbituric acid-reactive substances in the plasma (expressed as MDA levels) on day 43

\begin{tabular}{|c|c|c|c|c|c|c|c|}
\hline \multirow{2}{*}{ Observations } & \multicolumn{5}{|c|}{ Treatments ${ }^{1,2}$} & \multirow{2}{*}{ SEM } & \multirow{2}{*}{$P$-value } \\
\hline & $\mathrm{T} 1$ & $\mathrm{~T} 2$ & T3 & $\mathrm{T} 4$ & T5 & & \\
\hline \multicolumn{8}{|l|}{ Blood constituents } \\
\hline $\mathrm{PCV}^{3}(\%)$ & 31.5 & 30.9 & 31.1 & 28.1 & 31.3 & 0.514 & 0.181 \\
\hline $\mathrm{WBC}^{4}(\operatorname{cell} / \mu \mathrm{L})$ & 17,500 & 21,110 & 23,221 & 30,200 & 25,175 & 1,548 & 0.094 \\
\hline Heterophil (\%) & $41.3^{\mathrm{ab}}$ & $50.8^{\mathrm{a}}$ & $50.6^{\mathrm{a}}$ & $24.5^{\mathrm{b}}$ & $33.4^{\mathrm{ab}}$ & 2.719 & 0.003 \\
\hline Lymphocyte (\%) & $43.4^{\mathrm{b}}$ & $45.1^{\mathrm{b}}$ & $43.6^{\mathrm{b}}$ & $56.7^{\mathrm{a}}$ & $57.8^{\mathrm{a}}$ & 1.968 & 0.012 \\
\hline $\mathrm{H} / \mathrm{L}$ ratio $^{5}$ & $0.95^{\mathrm{ab}}$ & $1.13^{\mathrm{a}}$ & $1.17^{\mathrm{a}}$ & $0.44^{\mathrm{b}}$ & $0.59^{\mathrm{b}}$ & 0.076 & 0.001 \\
\hline \multicolumn{8}{|l|}{ Blood chemistry } \\
\hline Glucose (mg/dL) & $212^{\mathrm{a}}$ & $201^{\mathrm{a}}$ & $198^{\mathrm{ab}}$ & $183^{\mathrm{ab}}$ & $162^{\mathrm{b}}$ & 4.892 & 0.005 \\
\hline Triglyceride (mg/dL) & 38.6 & 32.6 & 26.7 & 24.1 & 26.8 & 4.892 & 0.056 \\
\hline Cholesterol (mg/dL) & $124^{\mathrm{a}}$ & $130^{\mathrm{a}}$ & $129^{\mathrm{a}}$ & $107^{\mathrm{ab}}$ & $99.9^{\mathrm{b}}$ & 3.217 & 0.002 \\
\hline $\operatorname{MDA}^{6}(\mathrm{nmol} / \mathrm{mL})$ & 3.03 & 3.00 & 2.97 & 2.94 & 2.94 & 0.014 & 0.233 \\
\hline $\begin{array}{l}{ }^{1} \text { Treatments: T1 control, } \\
\text { T4 JNR powder }(0.13 \% \\
{ }^{2} \text { Mean value from six re } \\
{ }^{3} \text { Packed cell volume } \\
{ }^{4} \text { White blood cell count } \\
{ }^{5} \mathrm{H} / \mathrm{L} \text { ratio was calculatec } \\
{ }^{6} \mathrm{Malondialdehyde} \text { conce } \\
{ }^{\mathrm{a}-\mathrm{b}} \text { Means in the same rov }\end{array}$ & $\begin{array}{l}\text { ilamycin, } \\
\text { onoid), an } \\
\text { ions per tr }\end{array}$ & $\begin{array}{l}\text { crude eth } \\
\text { JNR po } \\
\text { ent. }\end{array}$ & $\begin{array}{l}\text { extract } \\
(0.26 \%\end{array}$ & $\begin{array}{l}\text { of Jakr-N } \\
\text { noid). }\end{array}$ & ai (JNR) & les $(0.13$ & avonoid), \\
\hline
\end{tabular}


Table 5. Effect of treatments on the total bile acid concentrations (TBAC) and ileal nutrient digestibility coefficients on day 41

\begin{tabular}{|c|c|c|c|c|c|c|c|}
\hline \multirow{2}{*}{ Observation } & \multicolumn{5}{|c|}{ Treatment $^{1}$} & \multirow{2}{*}{ SEM } & \multirow{2}{*}{$P$-value } \\
\hline & $\mathrm{T} 1$ & $\mathrm{~T} 2$ & $\mathrm{~T} 3$ & $\mathrm{~T} 4$ & T5 & & \\
\hline TBAC $(\mathrm{mmol} / \mathrm{L})^{2}$ & $29.1^{\mathrm{b}}$ & $26.6^{\mathrm{b}}$ & $40.6^{\mathrm{a}}$ & $43.3^{\mathrm{a}}$ & $43.8^{\mathrm{a}}$ & 1.583 & 0.001 \\
\hline \multicolumn{8}{|c|}{ Ileal digestibility coefficients ${ }^{2,3}\left(\mathrm{DM}^{4}\right)$} \\
\hline Crude protein & 0.75 & 0.78 & 0.74 & 0.79 & 0.75 & 0.007 & 0.193 \\
\hline Ether extract & 0.78 & 0.79 & 0.79 & 0.79 & 0.79 & 0.008 & 0.987 \\
\hline
\end{tabular}

${ }^{1}$ Treatments: T1 control, T2 avilamycin, T3 crude ethanol extract (CEE) of Jakr-Na-Rai (JNR) granules (0.13\% flavonoid), T4 JNR powder $(0.13 \%$ flavonoid), and T5 JNR powder $(0.26 \%$ flavonoid $)$.

${ }^{2}$ Mean value from six replications per treatment on day 41 .

${ }^{3}$ Pooled ileal content samples from two birds per replication on day 41 .

${ }^{\mathrm{a}^{-b}}$ Means in the same row with different superscript letters are significantly different $(P<0.05)$.

${ }^{4} \mathrm{DM}=$ dry matter.

Table 6. Effect of treatments on the growth performance between days 22 to 41

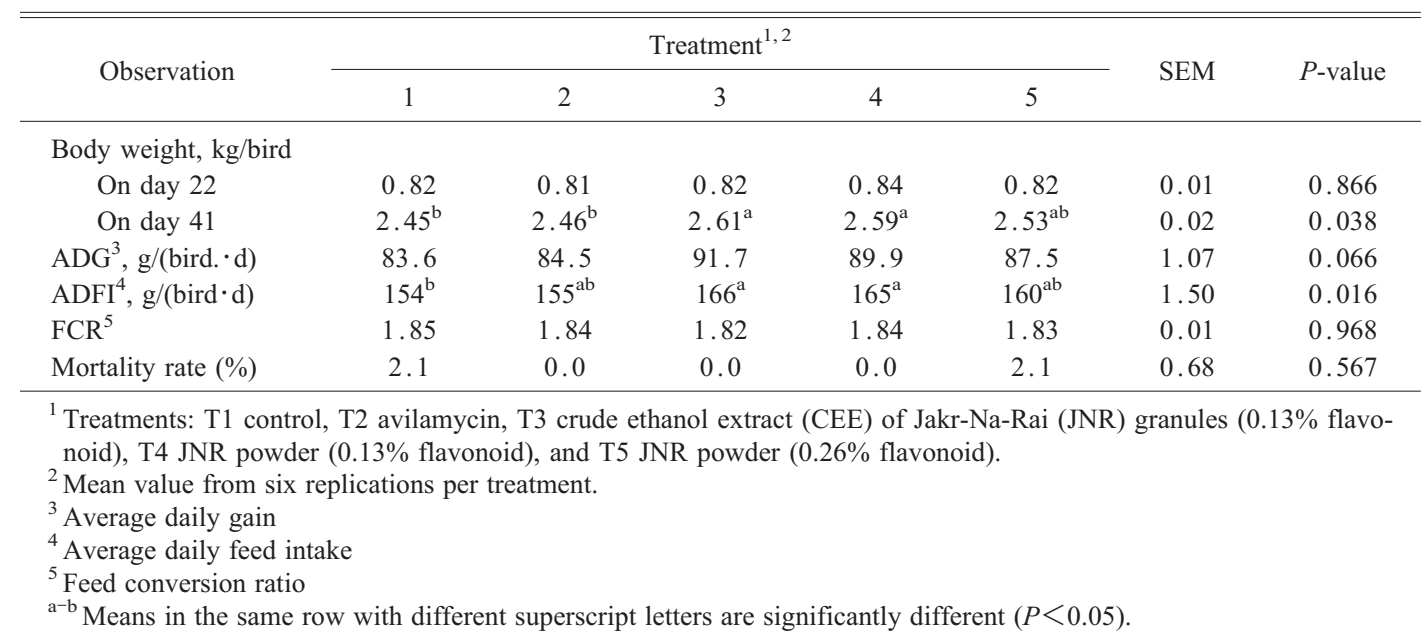

or antibiotic groups $(P=0.038)$, but this was not significantly altered by the inclusion of the higher level of JNR powder (Table 6). The average daily gain (ADG) of the birds showed only a numerical $(P=0.066)$ increase with the JNR diets, presenting the same trend as the average final BW. The average daily feed intake (ADFI) of broilers fed with diets containing the CEE form of JNR was higher than that in the control group $(P=0.016)$, while those fed with the powder form of JNR presented only a numerical increase in the ADFI, which was not affected by inclusion of the higher flavonoid level $(2.6 \mathrm{~g} / \mathrm{kg}$ of diet $)$ in both average final BW and ADFI. Finally, the feed conversion ratio (FCR) and mortality rate were not significantly different among all the groups.

\section{Carcass Fat Deposition and Lipid Peroxidation in the Breast Meat}

The live BW of fasted birds in all the treatment groups was not significantly different, but tended to decrease in the antibiotic and powder JNR diet groups, as did the carcass weight (Table 7), except that for the higher JNR powder dose (flavonoid level of $2.6 \mathrm{~g} / \mathrm{kg}$ of diet), which showed signifi- cantly lower carcass weight than in the control, antibiotic, and CEE JNR diet groups $(P=0.007)$. The percentage of abdominal fat was significantly lower in broilers fed with diets containing JNR powder at either dose compared to the control $(P=0.025)$; however, no significant difference in the percentage of abdominal fat was found in broilers fed with the CEE form of JNR compared to the control and antibioticfed groups. There was no significant effect of the treatments on drip loss or lipid peroxidation (MDA) in breast meat.

\section{Discussion}

The nutrient composition of all the experimental diets was similar, indicating that the results likely reflect the effect of dietary JNR. The blood PCV was used as a general health status indicator (Goodwin et al., 1991), while the WBC count (Al-Saffar and Al-Mawla, 2008) and H/L ratio (Post et al., 2003) were used as an indicator of stress. Bounouns and Stedman (2000) reported that the PCV and WBC count in normal broilers at $42 \mathrm{~d}$ of age were $22-35 \%$ and $12,000-$ 30,000 cells $/ \mu \mathrm{L}$, respectively. The values for PCV and WBC count recorded in this study were within these ranges, 
Table 7. Effect of treatments on the abdominal fat pad, drip loss, and thiobarbituric acid-reactive substances in breast meat (expressed as MDA levels) on day 43

\begin{tabular}{|c|c|c|c|c|c|c|c|}
\hline & \multicolumn{5}{|c|}{ Treatment $^{1,2}$} & \multirow{2}{*}{ SEM } & \multirow{2}{*}{$P$-value } \\
\hline & 1 & 2 & 3 & 4 & 5 & & \\
\hline Live weight $(\mathrm{kg} / \mathrm{bird})$ & 2.63 & 2.47 & 2.61 & 2.42 & 2.39 & 0.04 & 0.195 \\
\hline Carcass weight ${ }^{3}(\%)$ & $84.2^{\mathrm{a}}$ & $83.5^{\mathrm{a}}$ & $84.5^{\mathrm{a}}$ & $82.3^{\mathrm{ab}}$ & $80.4^{\mathrm{b}}$ & 0.44 & 0.007 \\
\hline Abdominal fat $(\%)$ & $1.93^{\mathrm{a}}$ & $1.63^{\mathrm{ab}}$ & $1.76^{\mathrm{ab}}$ & $1.40^{\mathrm{b}}$ & $1.41^{\mathrm{b}}$ & 0.06 & 0.025 \\
\hline Drip loss $(\%)$ & 0.96 & 0.97 & 0.97 & 0.97 & 0.97 & 0.002 & 0.539 \\
\hline $\mathrm{MDA}^{4}$ in breast meat $(\mathrm{mg} / \mathrm{kg})$ & 0.43 & 0.42 & 0.43 & 0.44 & 0.44 & 0.008 & 0.933 \\
\hline
\end{tabular}

\footnotetext{
${ }^{1}$ Treatments: T1 control, T2 avilamycin, T3 crude ethanol extract (CE $)$.
powder $(0.13 \%$ flavonoid), and T5 JNR powder $(0.26 \%$ flavonoid $)$.

${ }^{2}$ Mean value from six replications per treatment.

${ }^{3}$ Carcass weight without feathers, blood, and giblets.

${ }^{4}$ Malondialdehyde concentrations

${ }^{\mathrm{a}-\mathrm{b}}$ Means in the same row with different superscript letters are significantly different $(P<0.05)$.
}

indicating that the birds in all the groups were likely to be healthy. However, the $\mathrm{H} / \mathrm{L}$ ratio was significantly lower in birds fed on JNR powder at both levels compared to those fed with the other diets. Gross and Siegel (1983) reported that the $\mathrm{H} / \mathrm{L}$ ratio can be used as a more reliable stress indicator, showing less variation than the individual WBC profile, because stress stimulates corticosterone secretion and induces decreased $\mathrm{L}$ and increased $\mathrm{H}$ levels (Post et al., 2003; Thaxton et al., 2006). The JNR in granule form could not lower the $\mathrm{H} / \mathrm{L}$ ratio compared to the powder form at the same flavonoid level $(1.3 \mathrm{~g} / \mathrm{kg}$ of diet), indicating that JNR likely contains other active ingredients that were not extracted by ethanol. Yuchan et al. (2011) reported that JNR contained $2.52 \mathrm{~g} / \mathrm{kg}$ ascorbic acid, while Peña et al. (2008) reported a synergistic action between flavonoids and ascorbic acid in reducing stress.

The MDA level, as a product of lipid peroxidation, was used as an indicator for lipid peroxidation (Halliwell and Chirico, 1993). There was no significant difference in plasma MDA levels among all the groups, even though the $\mathrm{H} / \mathrm{L}$ ratio differed significantly between them. JNR exhibits prominent antioxidant activity due to chlorogenic acid, one of its phenolic compounds (Rodriguez de Sotillo and Hadley, 2002), but this may be attributed to the reduced peroxidation of pancreatic $\beta$-cells (Xu and Zhang, 2017). Damsawang et al. (2010) found that flavonoid phenolic compounds had the ability to decrease MDA levels, while Intajak et al. (2012) reported that a CEE of fresh JNR leaves exhibited antioxidative properties and could decrease the concentration of free radicals by $50 \%$ in vitro.

Blood glucose levels were determined after the chicks had fasted for $3 \mathrm{~h}$ as their maximum blood glucose response was reported to be from 50-240 min after feeding (Gutierrez del Alamo et al., 2009). The normal blood glucose level in broilers is reported to be in the range of $180-250 \mathrm{mg} / \mathrm{dL}$ (Hernawan et al., 2012). Diets supplemented with JNR powder at the $2.6 \mathrm{~g} / \mathrm{kg}$ flavonoid dose significantly decreased the broiler blood glucose and cholesterol levels. This may be due to active ingredients like flavonoids and polysaccharides that inhibit the activities of the enzymes $\alpha$-amylase and $\alpha$ glycosidase, leading to reduced levels of produced and absorbed glucose (Deng et al., 2011; Wu et al., 2011). Jiang et al. (2009) demonstrated that both flavonoids and polysaccharides (i.e., fructooligosaccharides) were the major ingredients in JNR for decreasing blood glucose levels, which was in agreement with $\mathrm{Li}$ et al. (2009) who found that crude water and $95 \%(\mathrm{v} / \mathrm{v})$ ethanol extracts of whole JNR plants at $0.4 \mathrm{~g} / \mathrm{kg}$ of BW could significantly decrease blood glucose levels in both normal and alloxan-diabetic mice. Similarly, a polysaccharide extract from whole JNR plants significantly decreased blood and urine glucose levels when fed to streptozotocin-induced diabetic rats at $0.4 \mathrm{~g} / \mathrm{kg}$ of BW (Deng et al., 2011). In this study, however, both the powder and the granule forms of JNR at the lower flavonoid level of $1.3 \mathrm{~g} / \mathrm{kg}$ did not decrease broiler blood glucose levels, which may reflect the lower polysaccharide contents of both forms (Chen et al., 2003; Wan et al., 2011a).

Silva et al. (2007) reported that the normal range of blood cholesterol in 42 -d-old broilers was $109-150 \mathrm{mg} / \mathrm{dL}$. In this study, blood cholesterol levels were significantly decreased in chicks receiving JNR powder at a flavonoid dose of 2.6 $\mathrm{g} / \mathrm{kg}$ of BW. Chen et al. (2003) reported that JNR contains $\beta$-sitosterol, which is known to inhibit cholesterol absorption in the small intestine, thereby reducing blood cholesterol levels (Matsuoka et al., 2008; Shi et al., 2011). The dietary JNR-mediated reduction in cholesterol levels observed in this study is in contrast to other studies (Aritajat et al., 2008; Keeratikajorn et al., 2012), but direct comparisons are not possible owing to the different plant parts, extraction methods, and species of test animal used, as well as the JNR dosage administered. Blood triglyceride levels in all the JNR-fed groups tended to be lower $(P=0.056)$ than those in the control and antibiotic-fed groups. Musa et al. (2007) showed that blood cholesterol levels have a positive correlation with blood triglyceride levels. The crude water extract of JNR had obvious effects on reducing triglyceride levels in experimental hyperlipidemia rats (Tong et al., 2012). 
Kaempferol is the main flavonoid in JNR responsible for increasing bile acid secretion (Powell et al., 2001; Crespy et al., 2003). In this study, the TBAC in the jejunum was used to represent the quantity of bile salt secreted into the small intestine. Bile salts help to emulsify lipids in the jejunum for micelle formation and increased fat absorption (Orban and Harmon, 2000). The TBAC was increased in chicks fed with a diet supplemented with either the powder or CEE form of JNR, which may have been due to the effect of kaempferol. Increasing the TBAC will likely increase the efficiency of fat emulsification, thereby improving its digestibility (Powell et al., 2001). However, the increased TBAC in chicks observed in this study did not elicit any beneficial effect on the ileal fat and protein digestibility coefficients. The ether extracts of the diets used in this study were moderately high, which required the activity of both pancreatic enzymes and bile acid to assimilate the fat. The kaempferol-mediated increase in the TBAC level would not evoke any beneficial effect on the digestibility coefficients of ileal nutrients as enzyme activity, and not bile salts, would be the limiting factor.

Compared to the control diet, supplementation with an antibiotic (avilamycin at $2.5 \mathrm{mg} / \mathrm{kg}$ ) did not elicit any beneficial effect on growth performance at the high stocking density used. Accordingly, avilamycin supplementation at a higher dose $(10 \mathrm{mg} / \mathrm{kg})$ in the broiler diet did not significantly affect the ADFI and FCR compared to control diet (Bozkurt et al., 2008). The average final BW of the 41-dold birds fed with either the JNR supplemented diet at a flavonoid level of $1.3 \mathrm{~g} / \mathrm{kg}$ was higher than that of birds in the control or antibiotic groups. The greater $\mathrm{BW}$ of birds in the JNR-fed groups may have been due to the higher ADFI. Although the ADFI is regulated by the energy requirements in birds (Hernawan et al., 2012), the ME was near identical in all the experimental diets. Therefore, theoretically, the ADFI should not be different and the observed higher ADFI may have been due to the lower blood glucose levels resulting from the flavonoid and polysaccharide content in JNR (Jiang et al., 2009). However, the FCR was not different among all the groups, which corresponded with the absence of any significant difference in ileal nutrient digestibility between the groups. No significant effect of JNR on broiler mortality was detected; the highest mortality rate in this study was $2.1 \%$, which lies within the normal range of $<4 \%$ (Oluremi et al., 2008).

The glucose-lowering effect of JNR was likely responsible for the high ADFI of the chicks, which increased to fulfill their energy needs. The way to provide the required energy was to break down glycogen followed by triglycerides (North, 1984). Since these birds had fewer glycogen deposits, they subsequently lost their deposited body fat. Abdominal fat has been used to represent net fat deposition in poultry (Griffiths et al., 1976). By day 43, the carcass weight and abdominal fat as a percentage of the live weight were significantly lower in the JNR powder-treated groups, whereas the live weight was not significantly lower. The JNR powder at either dose was marginally more effective than the CEE form at decreasing the percentage of abdominal fat. This may also reflect the higher polysaccharide level in the powder form that elicits increased blood glucose depletion than the CEE (Wan et al., 2011b). The percentage of carcass weight has been reported to correlate well $(r=$ 0.98 ) with the live bird weight (Olawumi, 2013). However, the live weight of random birds in both JNR powder-fed groups was smaller than that in the other groups, although the difference was not significant. The decreased carcass weight and fat deposition may be explained by the lighter BW of the live birds. When the live weight was considered for statistical analysis of both carcass and abdominal fat percentages using analysis of covariance (ANCOVA), the same non-significant trend was found for abdominal fat (data not shown), indicating that further investigation on fat deposition is needed.

The increased drip loss was likely due to the detrimental effects of free radicals on long-chain unsaturated fatty acids in the cell membranes, which leads to changes in cell structure and protein stability (Halliwell and Chirico, 1993). Denatured proteins lower the water absorbing and water retention capacity of the muscle (Huff-Lonergan and Lonergan, 2005). In this study, the production of free radicals may not have been sufficient to destroy the cell membranes, and, therefore, no significant difference in drip loss was observed in breast meat. This explanation could also be applied to the observed MDA levels in breast meat. Significant reductions in drip loss and MDA levels in the breast meat of animals with induced high free radical production were recorded with kaempferol dietary supplementation at $0.2 \mathrm{~g} / \mathrm{kg}$ of BW (Nirmala and Ramanathan, 2011). The positive correlation between drip loss and MDA levels in breast meat was confirmed by Xiao et al. (2013).

In conclusion, dietary inclusion of JNR powder at a flavonoid level of $1.3 \mathrm{~g} / \mathrm{kg}$ of diet in the grower-finisher period (22-43 d of age) of broilers was sufficient to lower the H/L ratio, blood glucose and cholesterol levels. Moreover, JNR powder supplementation increased the TBAC, promoted growth performance, and decreased the percentage of abdominal fat. The powder form of JNR produced better results than the CEE form at the same flavonoid level.

\section{Acknowledgments}

This study was funded by the $90^{\text {th }}$ Anniversary Ratchadaphiseksomphot Endowment Fund and the Faculty of Veterinary Science, Chulalongkorn University, Bangkok, Thailand. We would like to thank Dr. Robert Butcher under Ratchadaphiseksomphot Endowment Fund, Chulalongkorn University, for his English editing assistance.

\section{Conflicts of Interest}

The authors declare no conflict of interest.

\section{References}

Al-Saffar TM and Al-Mawla ED. Some hematological changes in chickens infected with ectoparasites. Iraqi Journal of Veterinary Sciences, 22: 95-100. 2008. 
Angkanaporn K, Ravindran V and Bryden WL. Additively of apparent and true ileal amino acid digestibility in soybean meal, sunflower meal, and meat and bone meal for broilers. Poultry Science, 75: 1098-1103. 1996.

Aritajat S, Saenphet K, Thaworn V and Wutteeraphol S. Effects of selected herbal extracts on blood chemistry profiles in rats. The Southeast Asian Journal of Tropical Medicine and Public Health, 39: 79-81. 2008.

Association of American Feed Control Official (AAFCO) Official Publication. Atlanta USA. 2000.

Association of Official Analytical Chemists (AOAC). Official Method of Analysis. 15 ${ }^{\text {th }}$ ed. Washington D.C. USA. 1990.

Bozkurt M, Küçükyilmaz K, Çatli AU and Çinar M. Growth performance and slaughter characteristics of broiler chickens fed with antibiotic mannanoligosaccharide and dextran oligosaccharide supplemented diets. International Journal of Poultry Science, 7: 969-977. 2008.

Bounouns DI and Stedman NL. Normal avian hematology chicken and turkey. $5^{\text {th }}$ ed. Veterinary Hematology. 1152-1153. 2000.

Chen L, Li HQ, Song HT and Zhang GG. A new cerebroside from Gynura divaricata. Fitoterapia, 80: 517-520. 2009.

Chen SC, Hong LL, Chang CY, Chen CJ, Hsu MH and Huang YC. Antiproliferative constituents from Gynura divaricata subsp. formosana. Chinese Pharmaceutical Journal, 55: 109-119. 2003.

Cheng G, Hao H, Xie S, Wang X, Dai M, Huang L and Yuan Z. Antibiotic alternatives the substitution of antibiotics in animal husbandry. Frontiers in Microbiology, 5: 1-14. 2014.

Cherian G, Wolfe FW and Sim JS. Dietary oils with added tocopherols effects on egg or tissue tocopherols, fatty acids and oxidative stability. Poultry Science, 75: 423-431. 1996.

Chong SY. Enzyme cycling methods and their application in clinical diagnostics. Diazyme Laboratories, 1-35. 2006.

Cobb. Cobb broiler performance and nutrition supplement. Cobb Vantress Inc. Siloam Springs. Arkansas. pp. 32-33. 2010.

Crespy V, Morand C, Besson C, Cotelle N, Vezin H, Demigne C and Remesy C. The splanchnic metabolism of flavonoids highly differed according to the nature of the compound. American Journal of Physiology-Gastrointestinal and Liver Physiology, 284: G980-G988. 2003.

Damsawang K, Wattanachant C, Wattanasit S and Itharat A. Effect of crude turmeric extract (Curcuma longa Linn.) supplementation on meat quality of broilers. Journal of Science and Technology Mahasarakham University, 29: 308-315. 2010.

Deng YX, Chen YS, Zhang WR, Chen B, Qiu XM, He LH, Mu LL, Yang $\mathrm{CH}$ and Chen R. Polysaccharide from Gynura divaricata modulates the activities of intestinal disaccharidases in streptozotocin-induced diabetic rats. British Journal of Nutrition, 106: 1323-1329. 2011.

Department of livestock development (DLD). Work instruction manual of standard broiler farm certification for standard livestock farm auditor (Thailand). Division of Livestock Standards, Department of Livestock Development. pp. 41-46. 2003.

Dong XF, Gao WW, Tong JM, Jia HQ, Sa RN and Zhang Q. Effect of polysavone (alfalfa extract) on abdominal fat deposition and immunity in broiler chickens. Poultry Science, 86: 1955-1959. 2007.

Feix JB, Bachowski GJ and Girotti AW. Photodynamic action of merocyanine 540 on erythrocyte membranes: structural perturbation of lipid and protein constituents. Biochimica et Biophysica Acta, 1075: 28-35. 1991.

Goodwin MA, Davis JF and Brown J. Packed cell volume reference intervals to aid in the diagnosis of anemia and polycythemia in young broiler chickens. Avian Diseases, 36: 440-443. 1991.

Griffin HD, Guo K, Windsor D and Butterwith SC. Adipose tissue lipogenesis and fat deposition in leaner broiler chickens. The Journal of Nutrition, 122: 363-368. 1992.

Griffiths L, Leeson S and Summers JD, Fat deposition in broilers effect of dietary energy to protein balance, and early life caloric restriction on productive performance and abdominal fat pad size. Poultry Science, 56: 638-646. 1976.

Gross WB and Siegel HS. Evaluation of the heterophil/lymphocyte ratio as a measure of stress in chickens. Avian Diseases, 27: 972-979. 1983.

Gutierrez del Alamo A, Verstegen MWA, Den Hartog LA, Perez de Ayala $\mathrm{P}$ and Villamide MJ. Wheat starch digestion rate affects broiler performance. Poultry Science, 88: 1666-1675. 2009.

Halliwell B and Chirico S. Lipid peroxidation; its mechanism, measurement, and significance. American Journal of Clinical Nutrition, 57: 15-25. 1993.

Hernawan E, Wahyuni S and Suprapti H. The level of blood glucose, triglyceride, final body weight and abdominal fat percentage of broiler under sex-separated and straight run rearing system. Lucraristiintifice - Seria Zootehnie, 57: 28-33. 2012.

Honikel KO. Reference methods for the assessment of physical characteristics of meat. Meat Science, 49: 447-457. 1998.

Huff-Lonergan E and Lonergan SM. Mechanisms of water-holding capacity of meat: The role of postmortem biochemical and structural changes. Meat Science 71: 194-204. 2005.

Intajak T, Srichairatanakool S and Kanjanapothi D. Antioxidant properties of the ethanolic extract from Gynura divaricata (L.) DC. The $2^{\text {nd }}$ STOU Graduate Research Conference. 1-10. 2012.

Jaiboon V, Boonyanuphap J, Suwansri S, Ratanatraiwong P and Hansawasdi C. Alpha amylase inhibition and roasting time of local vegetables and herbs prepared for diabetes risk reducing chili paste. Asian Journal of Food and Agro-Industry, 4: 103113. 2011.

Jiang MH, Hu JZ, Qiu WG, Qian Q, Tan M, Wu K and Qiu XM. Hypoglycemic and anti-anoxia effect of polysaccharide and flavonoids in Gynura divaricata (L.) DC. Chinese Journal of Hospital Pharmacy, 29: 1074-1076. 2009.

Keeratikajorn K, Pipatpaitoon N, Thunyodom S, Khanda S, Ittitanawong P and Kijparkorn S. Use of Jakr-Na-Rai (Gynura divaricata) as a roughage source on growth performance, blood constituent, blood glucose and cholesterol level in growing rabbits. Thai Journal of Veterinary Medicine, 42: 423-430. 2012.

Lammasak K. Effect of porcine bile powder on the digestibility of fat and protein, physiological changes of fat digestion and growth performance of starter broilers fed on high fat diet. Thesis of Chulalongkorn University, 55 p. 2010.

Li WL, Ren BR, Min-Zhuo M, Hu Y, Lu CG, Wu JL, Chen J and Sun S. The antihyperglycemic effect of plants in genus Gynura Cass. American Journal of Clinical Medicine, 37: 961-966. 2009.

Matsuoka K, Nakazawa T, Nakamura A, Honda C, Endo K and Tsukada M. Study of thermodynamic parameters for solubilization of plant sterol and stanol in bile salt micelles. Chemistry and Physics of Lipids, 154: 87-93. 2008.

Meex C, Poncin J, Chapelle JP and Cavalier E. Analytical validation of the new plasma calibrated Accu-Chek Test Strips (Roche Diagnostics). Clinical Chemistry and Laboratory Medicine, 44: 1376-1378. 2006.

Musa HH, Chen GH, Cheng JH and Yousif GM. Relation between abdominal fat and serum cholesterol, triglycerides, and lipo- 
protein concentrations in chicken breeds. Turkish Journal of Veterinary and Animal Sciences, 31: 375-379. 2007.

Nirmala $\mathrm{P}$ and Ramanathan M. Effect of kaempferol on lipid peroxidation and antioxidant status in 1, 2-dimethyl hydrazine induced colorectal carcinoma in rats. European Journal of Pharmacology, 654: 75-79. 2011.

North MO. Commercial chicken production manual. $3^{\text {th }}$ ed. Van Nostrand Reinhold. 17-20. 1984.

Olawumi SO. Phenotypic correlations between live body weight and carcass traits in arbor acre breed of broiler chicken. International Journal of Science and Nature, 4: 145-149. 2013.

Oluremi OIA, Mou PM and Adenkola AY. Effect of fermentation sweet orange (Citrus sinensis) fruit peel on its maize replacement value in broiler diet. Livestock Research for Rural Development, 20: 1-9. 2008.

Orban JI. and Harmon BG. Effect of bile supplementation on fat digestion in early weaned pig diets. Purdue University. pp. 1118. 2000.

Peña JEM, Vieira SL, López J, Reis RN, Barros R, Furtado FVF and Silva PX. Ascorbic acid and citric flavonoids for broilers under heat stress: effects on performance and meat quality. Brazilian Journal of Poultry Science, 10: 125-130. 2008.

Post J, Rebel JMJ and ter Huurne AA. Automated blood cell count: A sensitive and reliable method to study corticosterone-related stress in broilers. Poultry Science, 82: 591-595. 2003.

Powell AA, Larue JM, Batta AK and Martinez JD. Bile acid hydrophobicity is correlated with induction of apoptosis and/or growth arrest in HCT116 cell. Biochemical Journal, 365: 481-486. 2001.

Rodriguez de Sotillo DV and Hadley M. Chlorogenic acid modifies plasma and liver concentrations of cholesterol, triacylglycerol, and minerals in $(f a / f a)$, Zucker rats. Journal of Nutritional Biochemistry, 13: 717-726. 2002.

Roeder E, Eckert A and Wiedenfeld H. Pyrrolizidine alkaloids from Gynura divaricate. Planta Medica, 62: 386. 1996.

SAS. SAS User's guide: Statistics. NC: SAS Institute Inc. pp. 584. 2002.
Shi CL, Liu J, Wu F, Zhu X, Yew DT and Xu J. $\beta$-sitosterol inhibits high cholesterol-induced platelet $\beta$-amyloid release. Journal of Bioenergetics and Biomembranes, 43: 691-697. 2011.

Silva PRL, FreitasNeto OC, Laurentiz AC, Junqueira OM and Fagliari JJ. Blood serum components and serum protein test of Hybro-PG broilers of different ages. Brazilian Journal of Poultry Science, 9: 229-232. 2007.

Thaxton JP, Dozier WA, Branton SL, Meeorgan GW, Miles DW, Roush WB, Lott BD and Vizzier-Thaxton Y. Stocking density and physiological adaptive responses of broilers. Poultry Science, 85: 819-824. 2006.

Tong J, Li DX and Li XJ. Effect of Gynura Divaricata (Linn.) DC. extract on decreasing blood lipid in rat models with hyperlipideiam. Journal of Jiangxi University of TCM, 24(5): 70-2. 2012.

Wan C, Yu Y, Zhou S, Liu W, Tian S and Cao S. Antioxidant activity and free radical-scavenging capacity of Gynura divaricata leaf extracts at different temperatures. Pharmacognosy Magazine, 7: 40-45. 2011a.

Wan C, Yu Y, Zhou S, Tian S and Cao S. Isolation and identification of phenolic compounds from Gynura divaricata leaves. Pharmacognosy Magazine, 7: 101-108. 2011b.

Wu TT, Zhou XT, Deng YF, Jing Q, Li M and Yuan LJ. In vitro studies of Gynura divaricata (L.) DC extracts as inhibitors of key enzymes relevant for type 2 diabetes and hypertension. Journal of Ethnopharmacology, 136: 305-308. 2011.

Xiao HB, Fang J and Sun ZL. Kaempferitrin improves meat quality of broiler chickens. Czech Journal of Animal Science, 5: 227231. 2013.

$\mathrm{Xu}, \mathrm{BQ}$ and Zhang, YQ. Bioactive components of GYNURA DIVARICATA and its potential use in health, food and medicine: a mini-review. African Journal of Traditional Complementary and Alternative Medicines, 14 (3): 113-127. 2017.

Yuchan W, Lili H, Meng S, Hang XU, Shan C and Caiyun W. Determination and analysis on nutrient and medicinal components in different organs of Gynura divaricata (L.) DC. Journal of Changjiang Vegetables, 24: 1-9. 2011. 